\title{
Differential enrichment of TTF-I and Tip5 in the T-like promoter structures of the rDNA contribute to the epigenetic response of Cyprinus carpio during environmental adaptation.
}

\begin{tabular}{|c|c|}
\hline Journal: & Biochemistry and Cell Biology \\
\hline Manuscript ID & bcb-2016-0015.R1 \\
\hline Manuscript Type: & Article \\
\hline Date Submitted by the Author: & 11-Mar-2016 \\
\hline Complete List of Authors: & $\begin{array}{l}\text { Nardocci, Gino; Laboratorio de Biología Celular y Molecular, Departamento } \\
\text { de Ciencias Biológicas, Facultad de Ciencias Biológicas, Universidad Andrés } \\
\text { Bello, Quillota 980, Viña del Mar, Chile. } \\
\text { Simonet, Nicolas; Laboratorio de Biología Celular y Molecular, } \\
\text { Departamento de Ciencias Biológicas, Facultad de Ciencias Biológicas, } \\
\text { Universidad Andrés Bello, Quillota 980, Viña del Mar, Chile. } \\
\text { Navarro, Cristina; Laboratorio de Biotecnología Molecular, Departamento } \\
\text { de Ciencias Biológicas, Facultad de Ciencias Biológicas, Universidad Andrés } \\
\text { Bello, Av. Republica 217, Santiago, Chile. } \\
\text { Längst, Gernot; Institute for Biochemistry III, Biochemie-Zentrum } \\
\text { Regensburg, University of Regensburg, Regensburg, Germany. } \\
\text { Alvarez, Marco; Laboratorio de Biología Celular y Molecular, Departamento } \\
\text { de Ciencias Biológicas, Facultad de Ciencias Biológicas, Universidad Andrés } \\
\text { Bello, Quillota 980, Viña del Mar, Chile.; Interdisciplinary Center for } \\
\text { Aquaculture Research (INCAR), Victor Lamas 1290, PO Box 160-C, } \\
\text { Concepción, Chile }\end{array}$ \\
\hline Keyword: & $\begin{array}{l}\text { Acclimatization, Epigenetics, Homeostasis, Ribosomal genes, Nucleolar } \\
\text { Remodeling Complex }\end{array}$ \\
\hline
\end{tabular}

\section{SCHOLARONE ${ }^{\text {m }}$ \\ Manuscripts}




\section{Differential enrichment of TTF-I and Tip5 in the T-like promoter structures} of the rDNA contribute to the epigenetic response of Cyprinus carpio during environmental adaptation

Gino Nardocci ${ }^{1}$, Nicolas G. Simonet ${ }^{1}$, Cristina Navarro ${ }^{2}$, Gernot Längst ${ }^{3}$, Marco Alvarez ${ }^{1 \ddagger^{*}}$.

${ }^{1}$ Laboratorio de Biología Celular y Molecular, Departamento de Ciencias Biológicas, Facultad de Ciencias Biológicas, Universidad Andrés Bello, Quillota 980, Viña del Mar, Chile.

${ }^{2}$ Laboratorio de Biotecnología Molecular, Departamento de Ciencias Biológicas, Facultad de Ciencias Biológicas, Universidad Andrés Bello, Av. Republica 217, Santiago, Chile.

${ }^{3}$ Institute for Biochemistry III, Biochemie-Zentrum Regensburg, University of Regensburg, Regensburg, Germany.

${ }^{\ddagger}$ Interdisciplinary Center for Aquaculture Research (INCAR), Victor Lamas 1290, PO Box 160-C, Concepción, Chile

Email: marcoalvarez@unab.cl 


\section{Abstract}

To ensure homeostasis, ectothermic organisms adapt to environmental variations through molecular mechanisms. We previously reported that during the seasonal acclimatization of the common carp Cyprinus carpio, molecular and cellular functions are reprogrammed, resulting in distinctive traits. Importantly, the carp undergoes a drastic rearrangement of nucleolar components during adaptation. This ultrastructural feature reflects a fine modulation of rRNA gene transcription. Specifically, we identified the involvement of the transcription termination factor I (TTF-I) and Tip-5 (member of nucleolar remodeling complex, NoRC) in the control of rRNA transcription.

Our results suggest that differential Tip5 enrichment is essential for silencing carp ribosomal genes and that the $\mathrm{T}_{0}$ element is key for regulating the ribosomal gene during the acclimatization process. Interestingly, the expression and content of Tip5 were significantly higher in winter than in summer. Since carp ribosomal gene expression is lower in the winter than in summer, and considering that expression concomitantly occurs with nucleolar ultrastructural changes of the acclimatization process, these results indicate that Tip5 importantly contributes to silencing the ribosomal genes.

In conclusion, the current study provides novel evidence on the contributions of TTF-I and NoRC in the environmental reprogramming of ribosomal genes during the seasonal adaptation process in carp.

Keywords: Acclimatization, homeostasis, epigenetics, ribosomal genes, Nucleolar remodeling complex. 


\section{Introduction}

Ribosome-mediated protein synthesis is crucial to cell growth, proliferation, and adaptation to changing environments (Leary and Huang, 2001). Consequently, the transcription of ribosomal genes (rDNA) is a highly regulated process that responds to metabolic and environmental changes. Under these changes, the cell must finely control rDNA transcription to ensure sufficient ribosomes for protein synthesis (Grummt 2003).

Our laboratory previously reported that ribosomal RNA synthesis in the common carp Cyprinus carpio, a non-model organism, is reprogrammed as part of a physiological adaptation to seasonal environmental changes (Saez et al. 1984; Vera et al. 1993; Alvarez et al. 2006). This adaptation involves the phenotypic rearrangement of nucleolar components. During winter, fibrillar and granular components of the nucleolus are separated and surrounded by a thick layer of heterochromatin, and this ultrastructural feature is accompanied by a transient repression of ribosomal RNA transcription. This condition is reversed during the summer when active ribosomal biosynthesis is recovered. Therefore, the seasonal adaptation of carp involves a fine regulation of ribosomal transcription (Alvarez et al. 2006).

The rDNA genes exist in the nuclear genome as multiple copies of transcription units tandemly arrayed in clusters (Grummt 2003). In different organisms, the transcription units are flanked on both sides by terminator elements called T elements (McStay and Reeder, 1990; Evers and Grummt, 1995; Jacob 1995; Vera et al. 2003), which are recognized by the transcription terminator factor I (TTF-I). Binding of TTF-I to terminator elements downstream of the transcription unit $\left(\mathrm{T}_{1}-\mathrm{T}_{10}\right)$ stops the transcription of RNA polymerase I 
(Grummt et al. 1986). Interestingly, the binding of TTF-I to the element located immediately upstream of the ribosomal gene promoter, defined as $\mathrm{T}_{0}$, is a key event that facilitates the initiation of transcription for rDNA reconstituted into chromatin (Längst et al. 1997; Längst et al. 1998; Diermeier et al. 2013). Through this event, the TTF-I factor can then bind to the upstream terminator element and either activate or silence the transcription of rDNA genes by modifying the architecture of the promoter or by binding to the nucleolar remodeling complex (NoRC), respectively (Längst et al. 1998; Németh et al. 2004; McStay and Grummt, 2008).

The NoRC is a major complex involved in silencing rDNA genes through the recruitment of DNA methyltransferase and histone deacetylases to the rDNA promoter, thus promoting a closed chromatin state (Németh et al. 2004; Santoro and Grummt, 2005). The NoRC complex is formed by two components, an exclusive $205 \mathrm{kDa}$ protein identified as TTF-I Interacting protein 5 (Tip5) and SNF2h, a subunit with ATPase activity. This complex has been described in mice, humans, and, recently, in carp (Strohner et al. 2001; Santoro and Grummt, 2002; Fuentes et al. 2014).

Association of Tip5 with TTF-I leads to the recruitment of NoRC to the rDNA promoter, specifically in the $T_{0}$ element, thereby silencing ribosomal genes (Németh et al. 2004; McStay and Grummt, 2008; Strohner et al. 2004). Moreover, participation of TTF-I in the recruitment of NoRC indicates that this factor can coordinate an epigenetic regulation of ribosomal RNA transcription (McStay and Grummt, 2008). Recently, our group became the first to identify TTF-I and Tip5 in carp muscle tissue, in addition to characterizing seasonal transcriptional regulation in this fish. This finding suggests that these factors 
could be directly involved in the compensatory response of carp seasonal acclimatization (Fuentes et al. 2014).

Previously, we described that the carp presents T-like elements, both in the promoter and terminal regions of the ribosomal cistron (Vera et al. 2003). Interestingly, upstream of the transcription initiation site, two potentially regulatory elements, termed $T_{0}$ and $T_{0}{ }^{\circ}$, were identified. The latter $\left(T_{0}{ }^{\prime}\right)$ appears to be characteristic of the carp ribosomal cistron as this element has not been described in rDNA genes from other species. Moreover, the function of $T_{0}$ is still unknown.

Considering the importance of the $\mathrm{T}$ elements in the transcriptional regulation of rDNA genes, this study evaluated the interaction between the Tlike elements and TTF-I in carp to determine possible functions during seasonal acclimatization. Novel evidence was found that these factors are involved in the compensatory response of carp to seasonal acclimatization. Therefore, this work adds to understandings on how epigenetic mechanisms are involved in the fine regulation of ribosomal genes during a natural adaptive response. 


\section{Materials and Methods}

Animals and tissues: Adult male carp (1000-2000 g) were maintained under natural seasonal conditions as previously described (Araya et al. 2010). The fish were sacrificed, and liver samples were obtained, washed with PBS pH 7.4 (137 mM NaCl; $2.7 \mathrm{mM} \mathrm{KCl} ; 10 \mathrm{mM} \mathrm{Na} 2 \mathrm{HPO}_{4} ; 2$ mM KH $\mathrm{PO}_{4}$ ), and immediately processed or stored at $-80^{\circ} \mathrm{C}$ until required. This study adhered to animal welfare procedures and was approved by the Bioethical Committee of the Universidad Andrés Bello.

RT-qPCRs: Total RNA was purified from the liver using the TRIzol reagent (Invitrogen, Carlsbad, CA, USA). The quality of RNA was evaluated by electrophoresis and spectrophotometrically quantified. The cDNA was synthesized from $2 \mu \mathrm{g}$ of total RNA using M-MLV Reverse Transcriptase (Promega, Madison, WI, USA) and random primers according to the manufacturer's instructions. The resulting cDNAs were PCR-amplified in the GoTaq Green Master Mix (Promega, Madison, WI, USA) using the oligonucleotides shown in Table S1.

The RT-qPCR was performed with the appropriate oligonucleotides and the Brilliant SYBR Master Mix (Stratagene, Agilent Technologies, Santa Clara, CA, USA) in a final volume of $20 \mu \mathrm{L}$ and on an Mx3000P Real-Time PCR System (Stratagene, Agilent Technologies, Santa Clara, CA, USA). The average seasonal ratio of mRNA levels was calculated using the Pfaffl method (Pfaffl 2001), and carp mitochondrial 16S rRNA as a seasonally-constitutive gene expression. 
Chromatin immunoprecipitation (ChIP): ChIP assays were performed as previously described (Araya et al. 2010). For each assay, approximately $3 \times 10^{7}$ nuclei were isolated from hepatocytes of winter- and summer-acclimatized carp. Immunoprecipitations were performed with polyclonal anti-H3K9me3 (Abcam, Cambridge, UK), anti-H3K4me3 (Abcam, Cambridge, UK), anti-Tip5 (kindly provided by Dr. Längst), and anti-TTF-I (synthetized in this study). The immunoprecipitated DNA was amplified by qPCR on an Mx3000P Real-Time PCR System (Stratagene, Agilent Technologies, Santa Clara, CA, USA) using oligonucleotides (Table S1) corresponding to the $T_{0}$ and $T_{0}$ 'regions of carp rDNA (GeneBank Accession No AF133089.2). Real-time quantification was performed using the Brilliant SYBR Master Mix (Stratagene, Agilent Technologies, Santa Clara, CA, USA). The occupancy ratios of the $\mathrm{T}_{0}$ and $\mathrm{T}_{0}$. regions were calculated with the following formula:

$$
\begin{gathered}
\text { Occupancy ratio }=\left(\left(X_{a}-X_{\operatorname{lgG}}\right) / X_{\text {input }}\right) \times 100 \\
X \text { corresponds to: } \\
X=\log _{10}\left(\left(C_{t}-C_{t 0}\right) /-s\right.
\end{gathered}
$$

where "s" is the slope obtained for PCR efficiency in the calibration curve and $\mathrm{C}_{\mathrm{t} 0}$ is the averaged $\mathrm{Ct}$ obtained in the calibration curve for each oligonucleotide (Németh and Längst, 2008).

Nuclear extract and protein quantification: Nuclear extracts were prepared from liver tissue lysates in an $\mathrm{H}$ buffer $(250 \mathrm{mM}$ sucrose, $3 \mathrm{mM} \mathrm{CaCl}$, and 1 $\mathrm{mM}$ phenyl-methylsulfonyl fluoride in $20 \mathrm{mM}$ Tris $\mathrm{pH}$ 7.4). The subsequent procedures were performed as previously described (Araya et al. 2010). 
Nuclear proteins were quantified using the DC Universal Protein Assay Kit (BioRad, Hercules, CA, USA), and protein integrity was confirmed by SDS-PAGE.

Electrophoretic Mobility Shift Assays: Reactions (10 $\mu \mathrm{l})$ contained $500 \mathrm{fmol}$ of IR700- or IR800-labelled oligonucleotides (Table S1), electrophoretic mobility shift assay (EMSA) buffer (20 mM Tris- $\mathrm{HCl} \mathrm{pH} 7.0,80 \mathrm{mM} \mathrm{KCl,} 5 \mathrm{mM} \mathrm{MgCl}$, $0.2 \mathrm{mM}$ EDTA, 10\% glycerol, and $0.2 \mathrm{mM} \mathrm{DTT}$ ), and 250-1000 fmol of purified carp TTF-I. After incubation for $10 \mathrm{~min}$ at $30^{\circ} \mathrm{C}$, protein-DNA complexes were separated by electrophoresis on native $4.8 \%$ polyacrylamide gels and visualized with the Odysseys Infrared Imaging System (LI-COR, Lincoln, NE, USA).

Expression and purification of recombinant carp TTF-I: Primers were designed from the sequence previously obtained in our lab. ${ }^{20}$ The PCR product was cloned into the pET-15b expression vector (Novagen, Merck Millipore, Darmstadt, Germany). Rosetta 2 (DE3) pLys-competent cells were transformed with a pET-15b-TTF-I clone. Bacteria containing this clone were grown at $37^{\circ} \mathrm{C}$ with agitation in a minimal medium plus $50 \mathrm{mg} / \mathrm{mL}$ ampicillin and $33 \mathrm{mg} / \mathrm{ml}$ chloramphenicol until the log-phase. The cultures were subsequently induced with $1 \mathrm{mM}$ IPTG for $4 \mathrm{~h}$. The recombinant protein was purified with Ni-NTA according to the manufacturer's instructions (Qiagen, Germantown, MD, USA).

Western blot: For immunodetection, the polyclonal a-Tip5 (1:500), a-TTF-I (1:100), and $\alpha-H 2 B$ (Abcam, Cambridge, UK) (1:250) antibodies were used. Peroxidase-conjugated anti-rabbit $\lg G(\mathrm{H}+\mathrm{L})$ secondary antibodies were 
obtained from KPL (Gaithersburg, MD, USA). Protein-antibody complexes were visualized through the Enhanced Chemiluminescence (ECL) Detection System (Amersham Biosciences, Amersham, UK).

Preparation of TTF-I polyclonal antibodies: Specific carp TTF-I antibodies were prepared by BiosChile S.A. (Santiago, Chile) by immunizing two rabbits with the recombinant TTF-I protein.

Statistical Analysis: Each assay was performed in triplicate and repeated with three independent samples. Results are expressed as the mean \pm standard deviation (SD) of the mean for three different experiments. Statistical differences were assessed by an unpaired Student's $t$-test, with significance established at $p<0.05$. Statistical analyses were performed and graphs were constructed with the GraphPad Prism v.5 software (GraphPad Software Inc., La Jolla, CA, USA). 


\section{Results}

Expression of $C$. carpio TTF-I during acclimatization.

To assess the gene expression of TTF-I during seasonal acclimatization, qRT-PCR assays were performed on carp liver cells. TTF-I transcripts were detected in both seasons, with no significant differences between winter and summer (Fig. 1A). Likewise, TTF-I protein levels did not seasonally vary (Fig. 1B).

Considering the important role of Tip5 in ribosomal gene regulation (Németh et al. 2004; Strohner et al. 2004), the transcriptional expression of Tip5 was also evaluated in acclimatized carps. Tip5 expression significantly increased during the winter (Fig. 1A), a result supported by Western blot assays (Fig 1B). As a control, the expression of rDNA was analyzed during the process of seasonal acclimatization. In the summer, rRNA expression was significantly higher compared to winter. These results are consistent with our previous research (Vera et al. 1993; Alvarez et al. 2004; Alvarez et al. 2006).

In vitro interaction of recombinant TTF-I with C. carpio $\mathrm{T}_{0}$ and $\mathrm{T}_{0}$ elements. Our group previously studied the organization of the carp rDNA gene in detail (Vera et al. 2003). To investigate whether carp TTF-I has the ability to bind to the $T_{0}$ and $T_{0}$ ' elements, the recombinant protein was purified and EMSAs were performed (Fig. 2B). The probes for both carp T elements were able to bind with carp TTF-I. However, in mutant T elements, the electrophoretic mobility shift was abolished, thus demonstrating the binding specificity of this factor. 


\section{Evaluation of TTF-I enrichment in the $T_{0}$ and $T_{0}^{\prime}$ regions of $C$. carpio ribosomal genes during acclimatization.}

To evaluate the enrichment of TTF-I in carp T elements during the acclimatization process, ChIP assays were performed (Fig. 3). TTF-I was significantly enriched in both the $T_{0}$ and $T_{0}$ elements during the winter. Interestingly, this enrichment was clearly higher in $T_{0}$ (Fig. 3A).

In turn, Tip5 enrichment did not change in the $\mathrm{T}_{0}{ }^{\prime}$ element between winter and summer. However, there was significantly higher Tip5 enrichment in the $\mathrm{T}_{0}$ element during winter compared to summer (Fig. 3B).

To evaluate the chromatin state in carp $\mathrm{T}$ elements during the acclimatization process, ChIP assays were performed using antibodies against specific post-translational histone modifications associated with activation (H3K4me3) or repression (H3K9me3) (Fig. 3C and 3D, respectively) (Bernstein and Hake, 2006). The euchromatin mark, H3K4me3, was more abundant in both $\mathrm{T}$ elements during the summer than in the winter. Notably, this mark was more present in $T_{0}$ than $T_{0}$. On the other hand, H3K9me3 was significantly higher during the winter for both $\mathrm{T}_{0}$ and $\mathrm{T}_{0}{ }^{\circ}$. 


\section{Discussion}

An increasing number of studies indicate that different epigenetic mechanisms can coordinately act to regulate rDNA gene transcription (Hirschler-Laszkiewicz et al. 2001; Santoro and Grummt, 2001; Lawrence 2004; Grummt 2007; McStay and Grummt, 2008). However, few studies have explored the role of these mechanisms in a context influenced by natural environmental conditions (Araya et al. 2010; Simonet et al. 2013; Baulcombe and Dean, 2014).

Previous research by our group found that during the seasonal acclimatization process, C. carpio can modulate the expression of different genes (Kausel et al. 1999; Alvarez et al. 2001; Molina et al. 2002; Pinto et al. 2005). Specifically, carp can regulate the expression of ribosomal genes as part of a compensatory response to environmental stimuli.

Moreover, we reported that the carp ribosomal cistron has a $T_{0}$ element approximately 414 base pairs upstream of the transcription start site. Interestingly, we also identified another T element approximately 615 base pairs upstream of $T_{0}$. This element is termed $T_{0}{ }^{\circ}$, and its role remains unclear (Vera et al. 2003). In the present report, we evaluated the interaction of these $T$ elements with TTF-I to study possible functions during the seasonal acclimatization of the carp. Through EMSA, the specificity of carp TTF-I protein binding to both the $T_{0}$ and $T_{0}$ ' sequences was highlighted. When the $T$ probes were mutated in the specific nucleotides that contained the sequences of these elements, the binding was abolished, thus confirming specificity. These results support that both the $T_{0}$ and $T_{0}{ }^{\prime}$ elements are capable of binding with recombinant TTF-I. 
On the other hand, ChIP assays for TTF-I in the T elements during the adaptation process showed a differential enrichment of the TTF-I ribosomal cistron. In particular, the enrichment of carp TTF-I varied between winter and summer for $T_{0}$ and $T_{0}$ : In both cases, TTF-I was significantly more enriched during winter, but relative enrichment was higher in $T_{0}$. These results suggest that the regulatory role of TTF-I in the ribosomal gene during the adaptation process occurs mainly in the $T_{0}$ element, which is in agreement with its function in mice (Längst et al. 1998; Németh and Längst, 2004; McStay and Grummt, 2008). Regarding TTF-I expression and content, recent studies have shown that TTF-I levels are essential in the cell for efficient ribosomal biogenesis (Lessard et al. 2012). Carp TTF-I showed similar transcriptional expression and protein contents in winter- and summer-acclimatized fish. This result suggests that for correct cellular homeostasis during seasonal adaptation, TTF-I levels remain constant independent of the environmental stimuli. Therefore, the differential expression of ribosomal genes between winter and summer appears to occur independent of TTF-I levels. Consequently, TTF-I may play a role as a scaffold or pivot for other proteins that control rDNA expression during acclimatization.

TTF-I can interact with the NoRC complex through the Tip5 subunit, leading to the recruitment of the complex to the rDNA promoter, thus allowing ribosomal gene silencing (Stohner et al. 2004; Németh and Längst, 2004). Different studies show that Tip5 can repress rDNA transcription through interaction with other factors such as HDAC, DNMT, and HMT or even through the concentration of the Tip5 subunit itself. Therefore, Tip5 is essential for silencing the rDNA gene. Tip5 enrichment in carp $\mathrm{T}$ elements was evaluated 
during seasonal adaptation, with the results showing dramatic differences between $T_{0}$ and $T_{0}{ }^{\circ}$. Tip5 enrichment did not change in $T_{0}{ }^{\circ}$ during acclimatization. In contrast, there was significantly higher Tip5 enrichment in the $\mathrm{T}_{0}$ element during winter, but no binding was detected in the summer. Differential enrichment could be due to the contiguous $\mathrm{T}$ element sequences that can recognize Tip5, especially considering that this factor can bind by its AT-hooks elements to DNA (Stohner et al. 2001). Similarly, an alternative explanation could be different methylation states in these regions. In this respect, NoRC-mediated rRNA gene silencing requires the methylation of $\mathrm{CpG}$ at position 133 (Santoro et al., 2005), and in carp, we have observed hypermethylation of the proximal promoter during winter as compared to summer (Pinto et al., 2005). Unfortunately, we do not have information about the methylation state at position -1077 , which corresponds to $T_{0}{ }^{\prime}$ (Vera et al., 2003). Certainly, different methylation states of the DNA regions containing Telements could also explain the differentiated seasonal enrichments of Tip5.

These results suggest that differential Tip5 enrichment is essential for silencing carp ribosomal genes and that the $T_{0}$ element is key for regulating the ribosomal gene during the acclimatization process.

The present study evaluated epigenetic modification in the rRNA gene, specifically in the $\mathrm{T}$ elements, during the adaptation process of carp. The epigenetic mark of euchromatin, $\mathrm{H} 3 \mathrm{~K} 4 \mathrm{me} 3$, was more enriched in both $\mathrm{T}_{0}$ and $\mathrm{T}_{0}$ during summer. Notably, this mark was more enriched in $\mathrm{T}_{0}$, suggesting the importance of this element in the activation process of rDNA genes during acclimatization. Additionally, the repressive mark, H3K9me3, was more enriched during winter in both elements. These results are similar to that 
reported by Simonet et al. (2013), indicating the importance of the heterochromatin state in the ribosomal promoter. Specifically in Simonet et al. (2013), H3K4me3 enrichment was similar to the present study, where the mark was more present in $\mathrm{T}_{0}$, thus confirming the importance of this element.

All of our findings suggest that during the acclimatization process of Cyprinus carpio, there is an epigenetic modulation of the ribosomal genes. These genes pass from an active to repressive state during winter acclimatization, which is crucial for the homeostasis of this fish. During regulation, the epigenetic response is necessarily involved in different mechanisms, including NoRC, that play fundamental roles during the adaptation process. Furthermore, while other factors studied by our group, such as macroH2A and H2A.z, are not specific for ribosomal genes, they can act on other genes during acclimatization (Araya et al. 2010; Simonet et al. 2013)

In conclusion, our results provide novel evidence on how epigenetic mechanisms contribute to environmentally-stimulated genetic rDNA reprogramming during the seasonal adaptation of Cyprinus carpio. Epigenetic responses appear to be an efficient and gene-regulation mechanism for cell homeostasis. However, further studies are needed to define the molecular mechanism of these proteins in the control of rRNA synthesis during seasonal acclimatization. 


\section{Acknowledgements}

This study was supported by the following grants: FONDECYT 1120873, CONICYT/FONDAP 15110027, DFG-Conicyt 2009-083, and DI-07-09/I from UNAB. 


\section{References}

Alvarez M, Kausel G, Figueroa J, Vera MI. 2001. Environmental reprogramming of the expression of protein kinase CK2beta subunit in fish. Mol Cell Biochem 227(1-2): 107112.

Alvarez M, Molina A, Quezada C, Pinto R, Krauskopf M, Vera MI. 2004. Eurythermal fish acclimatization and nucleolar function: a review. Journal of Thermal Biology 29(7): 663-667.

Alvarez M, Quezada C, Molina A, Krauskopf M, Vera MI, Thiry M. 2006. Ultrastructural changes of the carp (Cyprinus carpio) hepatocyte nucleolus during seasonal acclimatization. Biol Cell 98(8): 457-463.

Araya I, Nardocci G, Morales J, Vera M, Molina A, Alvarez M. 2010. MacroH2A subtypes contribute antagonistically to the transcriptional regulation of the ribosomal cistron during seasonal acclimatization of the carp fish. Epigenetics Chromatin 3(1): 14.

Baulcombe DC, Dean C. 2014. Epigenetic regulation in plant responses to the environment. Cold Spring Harb Perspect Biol 6(9): a019471.

Bernstein E, Hake SB. 2006. The nucleosome: a little variation goes a long way. Biochem Cell Biol 84(4): 505-517.

Diermeier SD, Németh A, Rehli M, Grummt I, Längst G. 2013. Chromatin-Specific Regulation of Mammalian rDNA Transcription by Clustered TTF-I Binding Sites. PLoS Genet 9(9): e1003786.

Evers R, Grummt I. 1995. Molecular coevolution of mammalian ribosomal gene terminator sequences and the transcription termination factor TTF-I. Proc Natl Acad Sci USA 92(13): 5827-5831. 
Fuentes EN, Zuloaga R, Nardocci G, Fernandez de la Reguera C, Simonet N, Fumeron R, Valdes JA, Molina A, Alvarez M. 2014. Skeletal muscle plasticity induced by seasonal acclimatization in carp involves differential expression of rRNA and molecules that epigenetically regulate its synthesis. Comp Biochem Physiol B, Biochem Mol Biol 172-173: 57-66.

Grummt I, Rosenbauer H, Niedermeyer I, Maier U, Ohrlein A. 1986. A repeated 18 bp sequence motif in the mouse rDNA spacer mediates binding of a nuclear factor and transcription termination. Cell 45(6): 837-846.

Grummt I. 2007. Different epigenetic layers engage in complex crosstalk to define the epigenetic state of mammalian rRNA genes. Hum Mol Genet 16 Spec No 1: R21-7.

Grummt I. 2003. Epigenetic silencing of RNA polymerase I transcription. Nat Rev Mol Cell Biol 4(8): 641-649.

Grummt I. 2003. Life on a planet of its own: regulation of RNA polymerase I transcription in the nucleolus. Genes Dev 17(14): 1691-1702.

Hirschler-Laszkiewicz I, Cavanaugh A, Hu Q, Catania J, Avantaggiati ML, Rothblum LI. 2001. The role of acetylation in rDNA transcription. Nucleic Acids Res 29(20): 41144124.

Jacob ST. 1995. Regulation of ribosomal gene transcription. Biochem J 306(Pt 3): $617-626$.

Kausel G, Vera MI, San Martin R, Figueroa J, Molina A, Muller M, Martial J, Krauskopf M. 1999. Transcription factor pit-1 expression is modulated upon seasonal acclimatization of eurythermal ectotherms: identification of two pit-1 genes in the carp. J Cell Biochem 75(4): 598-609.

Längst G, Becker PB, Grummt I. 1998. TTF-I determines the chromatin architecture of 
the active rDNA promoter. EMBO J 17(11): 3135-3145.

Längst G, Blank TA, Becker PB, Grummt I. 1997. RNA polymerase I transcription on nucleosomal templates: the transcription termination factor TTF-I induces chromatin remodeling and relieves transcriptional repression. EMBO J 16(4): 760-768.

Lawrence RJ. 2004. Chromatin turn ons and turn offs of ribosomal RNA genes. Cell Cycle 3(7): 880-883.

Leary DJ, Huang S. 2001. Regulation of ribosome biogenesis within the nucleolus. FEBS Lett 509(2): 145-150.

Lessard F, Stefanovsky V, Tremblay MG, Moss T. 2012. The cellular abundance of the essential transcription termination factor TTF-I regulates ribosome biogenesis and is determined by MDM2 ubiquitinylation. Nucleic Acids Res 40(12): 5357-5367

McStay B, Grummt I. 2008. The epigenetics of rRNA genes: from molecular to chromosome biology. Annu Rev Cell Dev Biol 24: 131-157.

McStay B, Reeder RH. 1990. A DNA-binding protein is required for termination of transcription by RNA polymerase I in Xenopus laevis. Mol Cell Biol 10(6): 2793-2800.

Molina A, Corta A, Martin RS, Alvarez M, Burzio LO, Krauskopf M, Vera MI. 2002. Gene structure of the carp fish ribosomal protein L41: seasonally regulated expression. Biochem Biophys Res Commun 295(3): 582-586.

Németh A, Längst G. 2004. Chromatin higher order structure: opening up chromatin for transcription. Briefings in Functional Genomics and Proteomics 2(4): 334-343.

Németh A, Längst G. 2008. Chromatin organization of active ribosomal RNA genes. Epigenetics 3(5): 243-245.

Németh A, Strohner R, Grummt I, Längst G. 2004. The chromatin remodeling complex 
NoRC and TTF-I cooperate in the regulation of the mammalian rRNA genes in vivo. Nucleic Acids Res 32(14): 4091-4099.

Pfaffl MW. 2001. A new mathematical model for relative quantification in real-time RTPCR. Nucleic Acids Res 29(9): e45.

Pinto R, Ivaldi C, Reyes M, Doyen C, Mietton F, Mongelard F, Alvarez M, Molina A, Dimitrov S, Krauskopf M, Vera MI, Bouvet P. 2005. Seasonal environmental changes regulate the expression of the histone variant macroH2A in an eurythermal fish. FEBS Lett 579(25): 5553-5558.

Saez L, Zuvić T, Amthauer R, Rodríguez E, Krauskopf M. 1984. Fish liver protein synthesis during cold acclimatization: seasonal changes of the ultrastructure of the carp hepatocyte. J Exp Zool 230(2): 175-186.

Santoro R, Grummt I. 2005. Epigenetic mechanism of rRNA gene silencing: temporal order of NoRC-mediated histone modification, chromatin remodeling, and DNA methylation. Mol Cell Biol 25(7): 2539-2546.

Santoro R, Grummt I. 2001. Molecular mechanisms mediating methylation-dependent silencing of ribosomal gene transcription. Mol Cell 8(3): 719-725.

Santoro R, Li J, Grummt I. 2002. The nucleolar remodeling complex NoRC mediates heterochromatin formation and silencing of ribosomal gene transcription. Nat Genet 32(3): 393-396.

Simonet NG, Reyes M, Nardocci G, Molina A, Alvarez M. 2013. Epigenetic regulation of the ribosomal cistron seasonally modulates enrichment of H2A.Z and H2A.Zub in response to different environmental inputs in carp (Cyprinus carpio). Epigenetics Chromatin 6(1): 22.

Strohner R, Németh A, Jansa P, Hofmann-Rohrer U, Santoro R, Längst G, Grummt I. 
2001. NoRC-a novel member of mammalian ISWI-containing chromatin remodeling machines. EMBO J 20(17): 4892-4900.

Strohner R, Németh A, Nightingale KP, Grummt I, Becker PB, Längst. 2004. Recruitment of the nucleolar remodeling complex NoRC establishes ribosomal DNA silencing in chromatin. Mol Cell Biol 24(4): 1791-1798

Vera MI, Molina A, Pinto R, Reyes M, Alvarez M, Krauskopf E, Quezada C, Torres J, Krauskopf M. 2003. Genomic organization of the rDNA cistron of the teleost fish Cyprinus carpio. Biol Res 36(2): 241-251.

Vera MI, Norambuena L, Alvarez M, Figueroa J, Molina A, Leon G, Krauskopf M. 1993. Reprogramming of nucleolar gene expression during the acclimatization of the carp. Cell Mol Biol Res 39(7): 665-674. 


\section{Figure legends}

Figure 1. Differential expression of epigenetic factors during the acclimatization process.

Real-time qRT-PCR quantification of carp (A) TTF-I (upper), Tip5 (middle), and pre-rRNA (lower) expressions during the acclimatization process. The black and white columns indicate winter (W) and summer (S), respectively. For all experiments, the average expression of three independent experiments were graphed and quantified in triplicate. Bars indicate standard deviation ( $\pm S D$ ) of the mean. Student's $t$-test analyses rendered significant differences $(*=p<$ 0.05). (B) Western blot analysis of the carp. Nuclear proteins from the liver tissue of winter- and summer-acclimatized carp were used to evaluate the TTF-I (upper) and Tip5 (middle) contents. The same blot was then probed with antibodies against H2B histone (lower), which was used as a loading control.

Figure 2. Electrophoretic mobility shift assay.

(A) Schematic representation of the carp cistron. The regions evaluated in the experiments are indicated by asterisks. (B) Electrophoretic mobility shift assay using the carp $\mathrm{T}_{0}{ }^{\prime}$ (left) or $\mathrm{T}_{0}$ (right) elements as probes. Increasing amounts of recombinant carp TTF-I protein (250-1000 fmol) were incubated with an equimolar mixture of non-mutated (IR700-labelled) or mutated (IR800-labelled) carp T elements. In yellow, the overlay of the assay is shown. The arrow identifies the DNA-protein complex. The complexes were analyzed on $4.8 \%$ native polyacrylamide gels. 
Figure 3. Enrichment of epigenetic factors and marks in the ribosomal cistron of C. carpio.

(A) Chromatin immunoprecipitation analysis for the enrichment of TTF-I, (B) Tip5, (C) H3K4me3 (euchromatin), and (D) H3K9me27 (heterochromatin) on $\mathrm{T}_{0}^{\circ}$ and $T_{0}$ elements. Bars indicate standard deviation $( \pm S D)$ of the means. The black and white columns indicate winter (W) and summer (S), respectively. The graphs show the average expression of three independent experiments quantified in triplicate. Student's $t$-test analyses rendered significant differences $(*=p<0.05)$. 
A

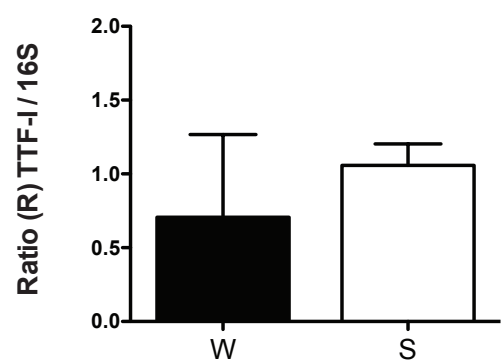

B
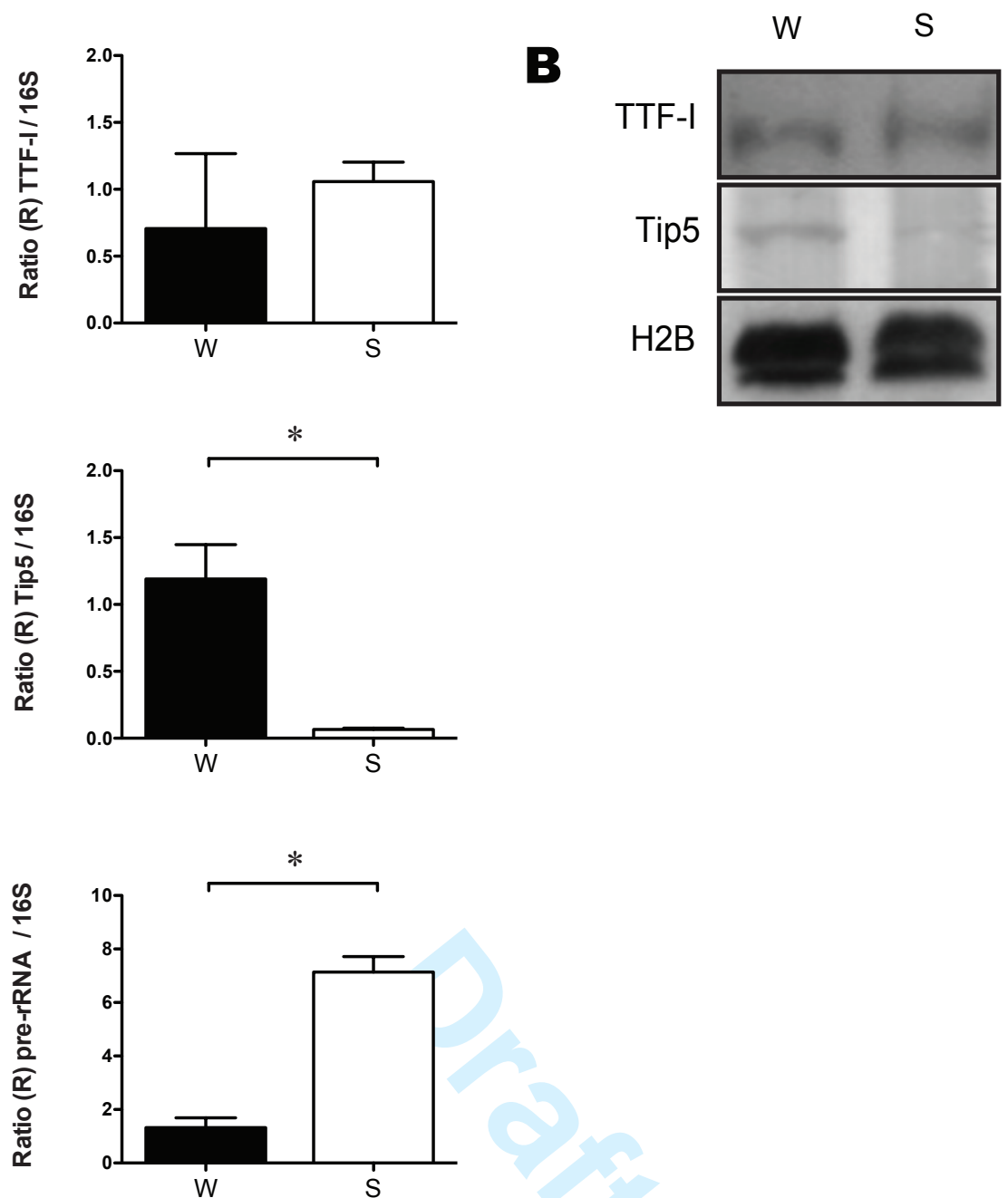
$\mathbf{A}$
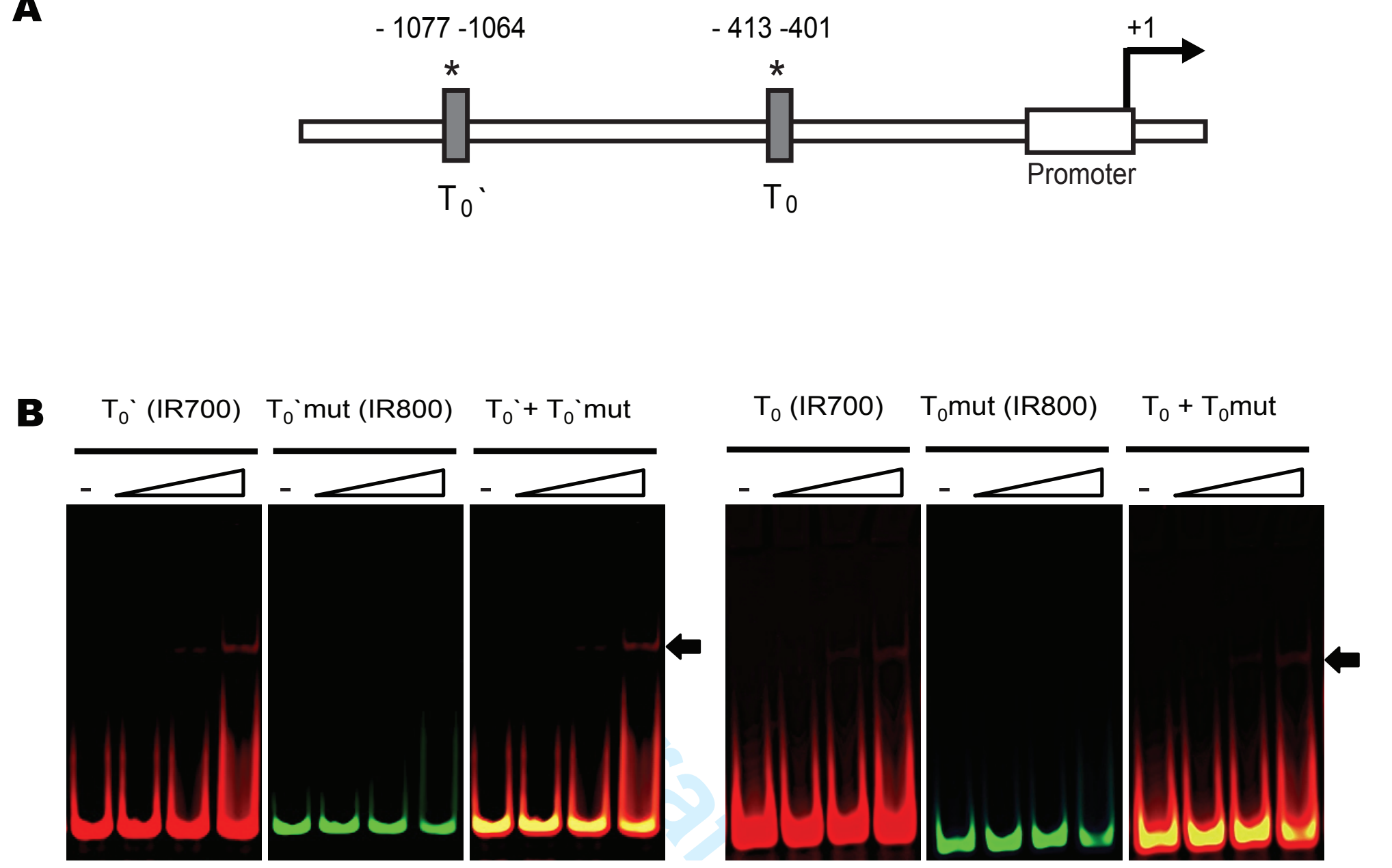
$\mathbf{A}$
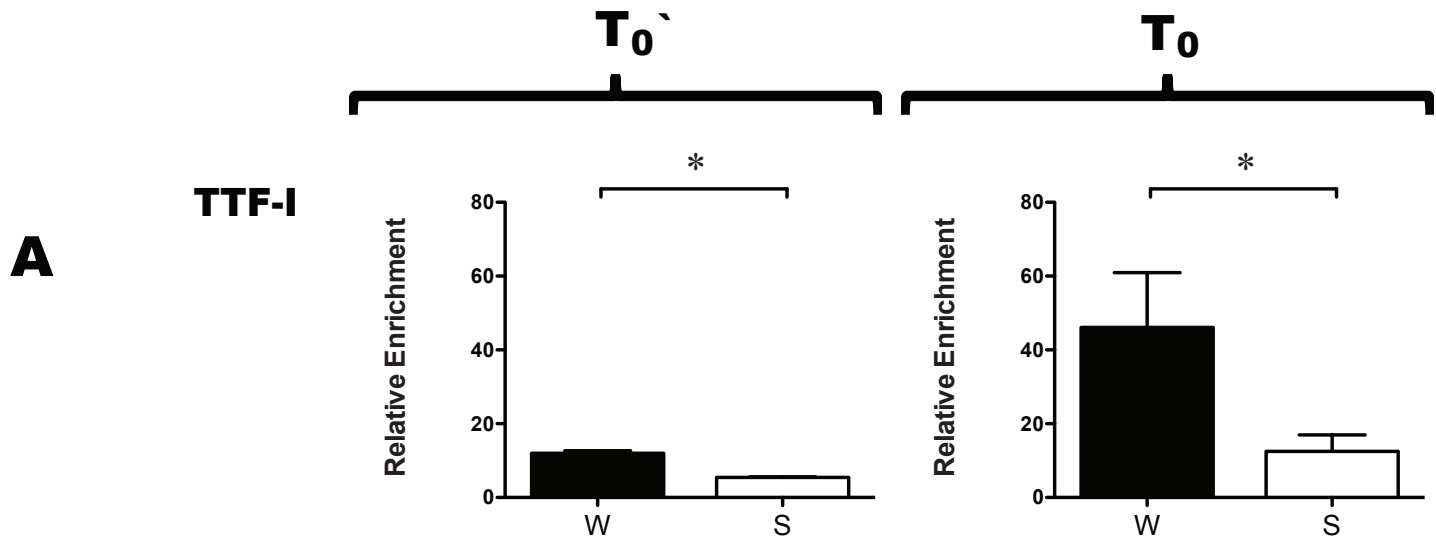

Tip5

B
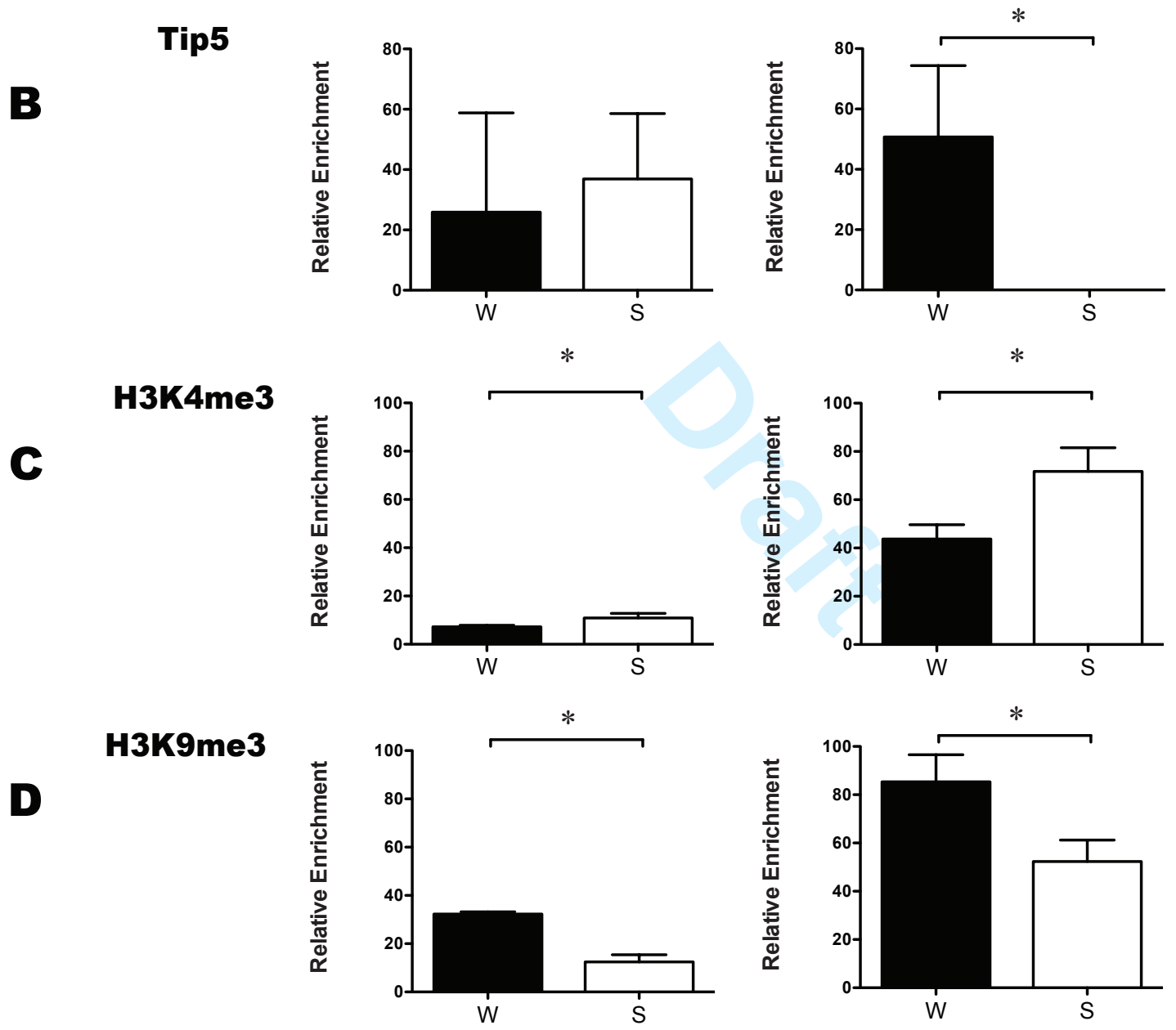